\title{
Ligas Acadêmicas: uma proposta discente para ensino, pesquisa e extensão
}

Academic Leagues: a student proposal for teaching, research and extension

\section{Diogo Antonio Valente Ferreira', Renata Nu- nes Aranha ${ }^{2}$ e Maria Helena Faria Ornellas de Souza ${ }^{3}$}

\section{Introdução}

As atuais Diretrizes Curriculares do Curso de Medicina preconizam a formação do médico generalista sob uma postura humanista, crítica e reflexiva, promovendo a articulação ensino - pesquisa - extensão e adotando como modelo pedagógico o papel ativo do aluno em seu processo de formação ${ }^{1}$. Entretanto, as reformas no currículo médico encontram barreiras em questões burocráticas e institucionais nas Universidades do país, principalmente nas públicas, levando alunos e docentes a criarem alternativas para suprir essa demanda na aprendizagem.

É com essa justificativa que crescem as atividades extracurriculares que se propõem a complementar as lacunas na graduação. Diversos estudos apontam para a relevância destas atividades na formação dos médicos brasileiros ${ }^{2,3,4,5}$. Taquete e colaboradores verificaram que $93,7 \%$ dos estudantes entrevistados da Faculdade de Ciências Médicas da Universidade do Estado do Rio de Janeiro tinham realizado pelo menos um estágio extracurricular durante a graduação ${ }^{2}$. Para Tavares e colaboradores, estas atividades são extremamente comuns e representam "parte importante do treinamento da maioria dos estudantes de medicina brasileiros, servindo claramente como complementação de seu treinamento sabidamente deficiente na maioria de nossas escolas"3. Dentre essas, as chamadas Ligas Acadêmicas (LA) vem crescendo vertiginosamente em todo país, caracterizando-se por um modelo idealizado e organizado por alunos sob a tutela de um professor coordenador, cuja função é auxiliar e orientar as atividades, objetivando estudar e se aprofundar em um determinado tema, atendendo as demandas em saúde da população. Embora não exista uma definição clara das LA, algumas considerações podem ser levantadas. Nos dicionários, a palavra "liga", além de sinônimo de ligação, significa aliança, pacto ${ }^{6}$. Uma

\begin{abstract}
Resumo
À luz das atuais Diretrizes Curriculares, o ensino médico vivencia hoje um crescimento de movimentos extracurriculares, como as Ligas Acadêmicas. Firmando-se no tripé ensino, pesquisa e extensão, as Ligas são caracterizadas por serem um espaço não engessado no qual os alunos assumem papel ativo no processo de aprendizado, diante de um modelo educacional em geral ineficiente, contemplando uma formação generalista, crítica e condizente com a atual realidade social. Muito mais do que atividades extracurriculares, as Ligas representam uma grande ferramenta para a construção do conhecimento, possibilitando a vivência da flexibilização curricular, de uma grade mais maleável, na qual se cria o espaço para buscas mais autênticas, com trajetórias de maior pertencimento e significado na escolha de cada um.
\end{abstract}

Palavras-chaves: Educação Médica; Currículo; Estudantes de Medicina; Ligas Acadêmicas

Área Temática: Saúde Linha de Extensão: Metodologias e Estratégias de Ensino/Aprendizagem
Aluno de graduação. UERJ. E-mail: dii.valente@gmail.com

Professora Adjuct. UERJ.E-mail: renata@renataranha.com br

3 Professora Associada. UERJ. E-mail: mariahelenaornellas@gmail.com 
Liga Acadêmica é, antes de tudo, uma associação estudantil, na qual alunos e professores pactuam em prol do fortalecimento da educação médica frente à sociedade do século XXI, abordando temas que muitas vezes são deixados de lado pela rígida estrutura curricular das Universidades brasileiras. Caberia aos estudantes a definição dos rumos da Liga, sob orientação de um ou mais professores. Desta forma, além de aulas, cursos, atividades de pesquisa e assistência em diferentes cenários da prática médica, é importante a inserção dos alunos na comunidade, por meio de atividades educativas, preventivas ou de promoção à saúde. Os objetivos seriam melhorar a qualidade de vida da população e adquirir mais experiência e conhecimento?

\section{Histórico}

Inicialmente idealizadas durante os anos de repressão da Ditadura Militar (1964-1985), as Ligas representaram o questionamento da essência do ensino universitário e dos problemas político-sociais vigentes ${ }^{8,9}$. As primeiras Ligas surgiram nessa lógica e se espalharam por todo país. Representaram um questionamento quanto ao ensino alienado no qual cada avanço técnico científico estava dissociado da realidade além-campus em meio às mudanças na epidemiologia das doenças quando as doenças infecto-parasitárias perderam espaço para a violência urbana, os acidentes automobilísticos e as doenças crônico-degenerativas.

Nos últimos anos houve profundas mudanças na sociedade brasileira, as quais influenciaram as abordagens de atenção à saúde e de reformas curriculares e fortaleceram o aparecimento das LA $^{8}$. Entre elas vale mencionar a Constituição de 1988, que elaborou o princípio da indissociabilidade entre ensino, pesquisa e extensão. Outro fato marcante foi a Lei de Diretrizes e Bases da Educação Nacional (LDB), criada em 1996, que definiu o papel da educação superior na prática, destacando o estímulo ao conhecimento dos problemas do mundo presente, assim como os nacionais e regionais. $\mathrm{O}$ resultado prático seria evidenciado na prestação de serviços à comunidade e no estabelecimento de uma relação de reciprocidade com a mesma. Dessa forma, atividades de extensão universitária procuram fazer com que pesquisas e estudos acadêmicos cheguem mais rapidamente à comunidade por meio da prática profissional ${ }^{10}$.

O movimento das Ligas é tão intenso que a Associação Brasileira de Educação Médica
(ABEM) criou a Associação Brasileira de Ligas Acadêmicas em Medicina (ABLAM), tentando reunir as Ligas de todo país ${ }^{11}$. De modo a orientar e organizar a criação das Ligas, a Direção Executiva Nacional dos Estudantes em Medicina (DENEM) criou um guia que serve como um tipo de receita a ser adaptada às demandas locais? ${ }^{7}$ Hoje, as LA estão presentes em grande parte das faculdades de medicina do país, sejam públicas ou privadas, contando inclusive com o apoio de organizações médicas, como é o caso das Ligas de Medicina Intensiva, reconhecidas pela Associação de Medicina Intensiva Brasileira (AMIB). Da mesma forma, pode-se citar o Congresso Brasileiro das Ligas de Trauma e Emergência (CoLT), que acontece anualmente desde 1999 e vem se destacando pela quantidade de participantes envolvidos ${ }^{8}$.

\section{Ensino}

Em geral, as LA surgem a partir de uma das áreas da medicina, como, por exemplo, a cardiologia ou a pediatria. Assim, uma Liga aborda o "quesito ensino" através de palestras, debates, discussão de casos, mesas redondas, seminários e de diversas outras formas, os temas relacionados ao seu campo de atuação. Estes podem ser como uma complementação do conteúdo ministrado regularmente no curso de graduação, seja por este ser incompleto, vista a grande complexidade e a enorme quantidade de informação, ou por interesse dos alunos. Neste caso, a liga representa um espaço onde os alunos podem se aprofundar num tema de interesse, inserindo a busca por trajetórias individuais durante os seis anos de faculdade. Deve-se ressaltar, no entanto, que as LA não têm por objetivo uma especialização precoce, mas sim complementar uma formação que a estrutura curricular não é capaz promover, sempre visando o conceito atual de saúde como bem-estar biopsicossocial e a formação generalista, conforme preconizado pelas Diretrizes Curriculares, ${ }^{12}$. Uma Liga pode surgir também não para complementar um conteúdo, mas como uma alternativa dos estudantes para suprir a falta de um determinado tema, como é o caso das $\mathrm{Li}$ gas de Oncologia e de Medicina Complementar e Integrativa (antes denominada Liga de Medicina Alternativa) da Universidade do Estado do Rio de Janeiro. No currículo da UERJ, os alunos não possuem uma disciplina que aborde o tema câncer de forma integral, estando o estudo destas doenças fragmentado e disperso ao longo de todas as outras disciplinas, sem receber a devida atenção visto ao 
seu perfil de morbi-mortalidade ${ }^{13,14}$. Da mesma forma, a estrutura curricular rígida e tradicionalista não deixa espaço para assuntos dentro da medicina que ainda são tratados com descaso, como as práticas de medicina complementar e integrativa, contrastando com a grande presença destas no território nacional ${ }^{15}$.

Novamente mostrando o caráter inovador desse movimento, as LA constituem um espaço no qual alunos assumem os seus respectivos processos de construção de aprendizado, o que possibilita a aplicação de metodologias de ensino consideradas mais eficazes do que o modelo tradicionalista do professor como transmissor da informação e o aluno como receptor. As Diretrizes Curriculares reafirmam as propostas da Organização Mundial de Saúde (OMS) e da Organização Pan-americana de Saúde (OPS), que privilegiam a construção de modelos de saúde orientados à comunidade e a metodologia de ensino baseada em problemas $(\mathrm{ABP})^{16}$. A Aprendizagem Baseada em Problemas (ABP) vem há mais de 30 anos sendo defendida e adotada em vários países do mundo ${ }^{17}$. Busca-se através dessa metodologia fornecer ao estudante condições de desenvolver habilidades técnico-cognitivas e atitudes que devem ser aplicadas tanto para o cuidado do paciente quanto para a construção da postura de estudar para aprender pelo resto da vida profissional. $\mathrm{O}$ objetivo é a autoformação pela busca ativa do conhecimento fazendo o aluno "aprender a aprender". É necessário gerar um novo modelo científico, biomédico e social que fundamente um paradigma educativo em função do indivíduo e da sociedade. Preconiza-se o desenvolvimento da interdisciplinaridade e de metodologias problematizadoras, o desenvolvimento da interação docência - assistência - pesquisa e uma formação generalista, no mesmo tempo que se objetiva, obviamente, formar os melhores especialistas ${ }^{18}$.

\section{Pesquisa}

O meio universitário é, por definição, voltado para a pesquisa e construção de conhecimentos. Durante as atividades nas LA, o aluno está continuadamente em contato com pesquisas, seja através de contato com periódicos recentemente publicados usados durantes as discussões, seja através da realização de atividades de pesquisa propriamente dita, seja em contato direto com convidados de outros centros de pesquisa. Assim, também possibilita a formação de novos pesqui- sadores, criando oportunidades para a publicação em revistas científicas, participação em congressos e espaços para futuros projetos de mestrado e doutorado. A pesquisa fundamenta-se, sobretudo, em levantamentos epidemiológicos como em atividades próprias de pesquisa básica e aplicada, focando a produção de conhecimento a partir de observação de um fato, levantamento de literatura associada e de tentativas de solucionar problemas.

\section{Extensão}

As LA permitem a criação de um campo de diálogo entre duas realidades antagônicas dentro da sociedade brasileira tão excludente e repleta de contrastes: a Universidade e a comunidade. Contraditoriamente, muitas vezes os produtos resultantes dos meios acadêmicos não chegam a quem de fato deveria chegar. A Universidade é, além de tudo, o local onde conceitos, ideias e inovações são criadas com o objetivo de sanar uma demanda necessária para a sociedade. Na Medicina, isso se traduz na formação de um profissional capaz de atuar em todas as esferas do conhecimento, sobretudo no Sistema Único de Saúde (SUS), aplicando seu conhecimento técnico dentro da realidade da população. A extensão corresponde à interface estudantes - comunidade, transformando o aluno em um agente de promoção de saúde e transformação social. Desta forma, as Ligas representam um espaço de vivências que superam o simples assistencialismo, sendo, na verdade, uma troca de aprendizado entre os futuros profissionais médicos e a comunidade, objetivando a busca por produtos palpáveis que atendam as demandas da população ${ }^{7}$ e a formação de um profissional apto a empregar uma medicina mais humanizada e condizente com as verdadeiras necessidades dos brasileiros. As Ligas representam um elemento para construção da cidadania, formando indivíduos mais críticos com uma visão mais humanista e comprometidos com a realidade social.

Resumidamente, a extensão universitária pode ser definida como

o processo educativo, cultural e científico que amplia, desenvolve e realimenta o ensino e a pesquisa, estabelece a troca de saberes entre a sociedade e a universidade e tem como consequências a produção e a democratização do conhecimento acadêmico e propicia a participação efetiva da comunidade na atuação da universidade ${ }^{19}$. 
A extensão é uma forma de produção/construção de conhecimento por meio da "experienci-ação" 20 indissociável do processo ensino-aprendizado, que possibilita a relação sujeito-objeto mediante a metodologia ativa da problematização ${ }^{21}$.

As atividades extensionistas das LA se constituem principalmente de ações em educação de saúde, focando em promoção desta e prevenção de doenças, sempre considerando a realidade do público-alvo. Aqui, observa-se outro ponto importante: o foco na medicina preventiva, muitas vezes deixada em segundo plano nos currículos tradicionais. Busca-se orientar quanto a hábitos de vida saudáveis, tendo a compreensão do indivíduo não como uma entidade meramente biológica, mas como o resultado de uma complexa interação biológica, psicológica e social, abandonando-se a medicina focada nos processos patológicos ${ }^{22}$.

\section{Considerações Finais}

As Ligas Acadêmicas representam hoje uma expressividade marcante dentro do Ensino Médico no Brasil. Marcam as lacunas da estrutura curricular e apontam para as verdadeiras necessidades da sociedade nem sempre contempladas ao longo dos tradicionais seis anos de graduação. Além disso, ressalta o papel ativo do aluno na construção do conhecimento, tornando a Universidade como um verdadeiro espaço para a construção da "aprendizagem ao longo da vida”. Representam um campo no qual se constroem novos papeis e novas aplicações para uma sociedade nova, marcada pela globalização e pela grande dinâmica social e demográfica, com constantes e novas demandas coletivas e individuais. Contribuem para o exercício da cidadania, a humanização da medicina e possibilitam a aplicação prática do profissional médico apto a trabalhar em equipe, lidando com diversos ramos profissionais da área da saúde, como na Liga de Gestão em Saúde da UERJ, composta por alunos de medicina, enfermagem, odontologia e nutrição ${ }^{23}$. Da mesma forma, permitem a aquisição de conhecimentos da área de administração, através da responsabilidade dos discentes de gerir o caminho das Ligas, tão necessários no atual mercado de trabalho.

Entretanto, as Ligas não representam a solução para os problemas observados nas Universidades brasileiras, pois não excluem a necessidade de uma real reforma curricular nem, tão pouco, devem ser simplesmente encaradas como parte do chamado "currículo paralelo" do estudante de medicina, na qual professores e alunos tentam fazer a complementação necessária seja por interesse de se aprofundar num assunto ou por tentar suprir as deficiências do currículo formal ${ }^{3}$. As Ligas vão mais além desses conceitos. São, na verdade, uma grande ferramenta para a construção do conhecimento, possibilitando a vivência da flexibilização curricular, de uma grade curricular mais maleável, na qual se cria o espaço para buscas mais autênticas, com trajetórias de maior pertencimento e significado na escolha de cada um. É a permanência desse espaço não engessado que surge uma nova atuação, que precisará ser acompanhada de avaliações permanentes para incorporação ou não do descoberto. Também é neste espaço extra que surge, da observação atenta, da necessidade e da qualidade de troca comunidade-discentes-docentes, a possibilidade de inovação no processo ou no conteúdo do aprendizado.

Retomando a etimologia, "liga" é a forma substantivada do verbo "ligar". É isso que esse movimento acadêmico propicia: ligar Universidade e comunidade na constante troca de conhecimentos, trazendo contribuições para ambos os lados; ligar o currículo de forma a diminuir a fragmentação do conhecimento e "ligar" os alunos na busca ativa do aprender. Trata-se de um vasto assunto dentro da literatura sobre educação médica, com poucos estudos ainda publicados, mas com potencial para se fortalecer cada vez mais.

\section{Não há conflitos de interesse}

\section{Contribuição dos autores}

Diogo Antonio Valente Ferreira realizou a revisão bibliográfica, elaborou o conteúdo e realizou a dissertação do texto.

Renata Nunes Aranha contribuiu na elaboração e revisão do texto.

Maria Helena Faria Ornellas de Souza contribuiu na elaboração e revisão do texto.

\section{Referências}

1. BRASIL. Ministério da Educação. Conselho Nacional de Educação. Diretrizes Nacionais do Curso de Graduação em Medicina [online]. Resolução CNE/CES n ${ }^{\circ} 4$ de 7 de novembro de 2001. Disponível em: <www.mec.gov.br/cne/resolucao.shtm\#3>. Acesso em: 17 mar. 2010.

2. TAQUETE, S. R.; COSTA-MACEDO, L. M.; ALVARENGA, F. B. F. Currículo paralelo: uma realidade na formação dos estudantes de medicina da UERJ. Revista Brasileira de Educação Médica. 2003. Vol. 27, n. 3. p. 171-6. 
3. TAVARES, A. P.; FERREIRA, R. A.; FRANÇA, E. B.; et al. O "Currículo Paralelo" dos Estudantes de Medicina da Universidade Federal de Minas Gerais. Revista Brasileira de Educação Médica. 2007. Vol. 31, n. 3. p. 254-265.

4. PERES, C. M.; ANDRADE, A. S.; GARCIA, S. B. Atividades Extracurriculares: Multiplicidade e Diferenciação Necessárias ao Currículo. Revista Brasileira de Educação Médica. 2007. Vol. 31, n. 3. p. 203-211.

5. FERREIRA, N. M. A extensão universitária na formação do ensino médico. Boletim Virtual da Associação Brasileira de Associação Médica - ABEM [online]. 2007. p. 22. Disponível em: <www.educmed.org.br-publicacoes-boletimvirtual>. Acesso em: 31 mar. 2010

6. FERREIRA, A. B. H. Mini-Aurélio do Século XXI: o minidicionário da língua portuguesa. 4. ed. Rio de Janeiro: Nova Fronteira, 2000. 790 p.

7. AZEVEDO, R. P.; DINI, P. S. Guia para construção de Ligas Acadêmicas. Ribeirão Preto: Assessoria Científica da Direção Executiva Nacional dos Estudantes de Medicina, 2006. Disponível em: <http://www.daab.org.br/texto. asp?registro=157>. Acesso em: 15 mai. 2010.

8. Liga de Emergência e Trauma da Universidade Federal de Pernambuco. LETUFPE. Ligas Acadêmicas no Brasil Disponível em: <http://www.grupos.com.br/ blog/letufpe>. Acesso em: 27 mar. 2010.

9. MAFRA, S. Ligas acadêmicas. Diretórios Acadêmicos, v.2, n.7, 2006. Disponível em: <http://revista.cremepe.org. br/07/diretorios_academicos.php>. Acesso em: 7 out. 2008.

10. SALGADO FILHO N. Ligas Acadêmicas: veículo de interação com a comunidade. Universidade Federal do Maranhão (UFMA), 2007. Disponível em: <http://www.huufma.br/site/web/palavradiretor/palavra2.html>. Acesso em: 17 mar. 2010.

11. TORRES, A. R.; OLIVEIRA, G. M.; YAMAMOTO, F. $\mathrm{M}$; et al. Academic Leagues and medical education: contributions and challenges. Interface - Comunicação, Saúde, Educação. 2008. v. 12, n. 27. p. 713-720.

12. RODRÍGUEZ, C. A.; KOLLING, M. G.; MESQUITA, P. Educação em Saúde: um Binômio que Merece ser Resgatado. Revista Brasileira de Educação Médica. 2007. Vol. 31, n. 1. p. 60-66.

13. VALENTE-FERREIRA, D. A.; DA SILVA, C. N.; MONTEIRO, C. S.; et al. Oncologia na formação médica: uma estratégia para o fortalecimento da Política Nacional do Controle do Câncer. In: Congresso Brasileiro de Cancerologia, 18. 2009 out. 28-31. Anais... Curitiba, Brasil. Curitiba: CONCAM, 2009. p. 571.
14. VALENTE-FERREIRA, D. A.; MORAES, R. C. F.; MAKITA, L. S.; et al. Liga de Oncologia da UERJ: Qualificação Profissional e Ação Social. In: Congresso Científico do Hospital Universitário Pedro Ernesto, 48. 2010 ago. 23-27; Rio de Janeiro, Brasil. Anais... Rio de Janeiro: HUPE-UERJ, 2010. p. 84.

15. MIRANDA, F.; MOURÃO, A. F. V.; LOPES, R. C.; et al. Ampliando a visão de saúde com práticas alternativas [CD ROM]. In: Mostra de Extensão do UERJ Sem Muros, 21. 2010 set. 27- out. 1. Rio de Janeiro, Brasil. Rio de Janeiro: UERJ, 2010. p. 210.

16. MITRE, S. M.; SIQUEIRA-BATISTA, R.; GIRARDI-DE-MENDONÇA, J. N.; et al. Metodologias ativas de ensino-aprendizagem na formação profissional em saúde: debates atuais. Revista Ciência \& Saúde Coletiva. 2010. Disponível em: $<$ http://www.scielo.br/scielo.php?script=sci_ arttext\&pid=S1413-81232008000900018\&lng=pt\& $n r m=i$ so >. Acesso em: 31 mar. 2010

17. GOMES, R.; BRINO, R. F.; AQUILANTE, A. G.; et al. Aprendizagem Baseada em Problemas na formação médica e o currículo tradicional de medicina: uma revisão bibliográfica. Revista Brasileira de Educação Médica. 2009; Vol. 33, n. 3. p. 444-451.

18. ALMEIDA, M. J. A Educação Médica e Algumas Propostas de Mudanças: Alguns Antecedentes Históricos. Revista Brasileira de Educação Médica. 2001; Vol. 5, n. 2. p. 42-52.

19. Fórum de pró-reitores de extensão das universidades públicas brasileiras e SESU/MEC. Avaliação Nacional da Extensão Universitária, apresentando o Plano Nacional de Extensão Universitária. Brasília: Atual UESC, 2001.

20. MACHADO, C. L. B. Experienciação e a formação de educadores. In: Endipe -Encontro Nacional de Didática e Prática de Ensino, 18. [CD ROM]; 2008, abril 27 - 30; Porto Alegre: PUC-RS; Unisinos; 2008, p.12.

21. PONTE, C. I. R. V.; TORRES, M. A. R.; MACHADO, C. L. B.; et al. Extensão universitária na Famed/ UFRGS: cenários de formação profissional. Revista Brasileira de Educação Médica. 2009. Vol. 33, n. 4. p. 527-534.

22. BRIANI, M.C. História e construção social do currículo na educação médica: a trajetória do curso de medicina da Faculdade de Ciências Médicas da UNICAMP. Campinas-SP: 2003. Mestrado [Dissertação] - Universidade Estadual de Campinas, Faculdade de Educação. 226 fls.

23. MELLO, P. P. M.; BATISTA, L. P.; CRUZ, H. T.; et al. Liga Acadêmica de Gestão em Saúde [CD ROM]. In: Mostra de Extensão do UERJ Sem Muros, 21. 2010 set. 27- out. 1. Rio de Janeiro, Brasil. Rio de Janeiro: UERJ, 2010. p. 279.

\section{Abstract}

In face of current Curriculum Guidelines, medical education is experiencing a growth of extracurricular movement, as the Academic Leagues. Based in teach, research and extension, the leagues are characterized by a space in which students take an active role in learning process, in face of a educational model in general inefficient, contemplating a generalist and critic education, in consonance with current social reality. More than extracurricular activities, the leagues are a great instrument for knowledge construction, enabling the experience of curricular flexibility, a malleable shortcut, a space for authentic quests, with more meaning in each one choice.

Keywords: Medical Education; Curriculum; Medical Students; Academic Leagues 